\title{
A Novel Model of Cardiovascular Risk Based on Kidney Function
}

\author{
Robert N. Foley ${ }^{a, b}$ Allan J. Collins ${ }^{a, b}$ \\ ${ }^{a}$ Chronic Disease Research Group, Minneapolis Medical Research Foundation, and b Department of Medicine, \\ University of Minnesota, Minneapolis, Minn., USA
}

\section{Key Words}

Cardiovascular events - Estimated glomerular filtration rate $\cdot$ Sensitivity $\cdot$ Specificity $\cdot$ Risk triage

\begin{abstract}
Background/Aims: Although creatinine-based estimated glomerular filtration rate (eGFR) is associated with cardiovascular events, threshold values for optimum discrimination are unclear. We aimed to identify serum creatinine and eGFR thresholds of maximum sensitivity and specificity ( $\operatorname{Max}_{\mathrm{Sn}+\mathrm{Sp}}$ ) for a composite outcome of coronary heart disease, stroke, and death. Methods: Classification tree methodology defined the hierarchical rank of serum creatinine, eGFR, and cardiovascular risk factors in adults aged $45-64$ years (Atherosclerosis Risk in Communities Study, $n=15,582$; followup, 13.1 years). The Chronic Kidney Disease Epidemiology Collaboration (CKD-EPI), Modification of Diet in Renal Disease (MDRD) Study, and Cockcroft-Gault corrected for body surface area (CG/BSA) eGFR equations were used. Results: The mean study population age was 54.2 years; $26.4 \%$ were African-American. The mean standardized creatinine level was $0.83 \mathrm{mg} / \mathrm{dl}$. The mean eGFR $\mathrm{CKD}_{\text {-EPI, }}$ eGFR $\mathrm{MDRD}_{\text {, }}$ and eGFR $_{C G / B S A}$ values were $95.7,98.6$, and $99.7 \mathrm{ml} / \mathrm{min} / 1.73 \mathrm{~m}^{2}$, respectively. The composite outcome occurred for $22.1 \%$ of the population. For all eGFR measures, sensitivity was $<0.05$ and specificity $>0.98$ for thresholds of $60 \mathrm{ml} / \mathrm{min} / 1.73 \mathrm{~m}^{2}$. Max $_{\mathrm{Sn}+\mathrm{Sp}}$ for serum creatinine occurred at $0.73 \mathrm{mg} / \mathrm{dl}$ (sensitivity $0.66 /$ specificity 0.48 ); corresponding values for eGFR $_{\text {CKD-EPI, }}$ eGFR $\mathrm{CG}_{\text {BSSA, }}$ and eGFR $\mathrm{MDRD}_{\text {were }} 95(0.52 / 0.59)$,
\end{abstract}

$90(0.44 / 0.67)$, and $75(0.16 / 0.91) \mathrm{ml} / \mathrm{min} / 1.73 \mathrm{~m}^{2}$, respectively. Considering optimum thresholds for 10 modifiable risk factors, high-density lipoprotein cholesterol $\leq 44 \mathrm{mg} / \mathrm{dl}$ ranked first; rankings for optimum renal function thresholds varied between sixth and tenth. Conclusions: Optimum eGFR thresholds for community-based risk triage were substantially higher than $60 \mathrm{ml} / \mathrm{min} / 1.73 \mathrm{~m}^{2}$, which currently defines moderate abnormality. Utility of creatinine-based risk triage in older adults appears modest.

Copyright $\odot 2011$ S. Karger AG, Basel

\section{Introduction}

As chronic kidney disease is widespread, usually silent, and associated with cardiovascular disease, it appears rational to question whether screening for renal dysfunction in community-dwelling adults would be useful, mirroring efforts regarding more familiar risk factors like lipids, blood pressure, body mass index, and blood glucose [1-3]. Before advocating screening with renal function measures for cardiovascular prevention, it would be useful to examine how different threshold levels predict the occurrence of future episodes of cardiovascular disease. Considered within finite intervals of follow-up, thresholds at which 'normal' values are associated with low cardiovascular event rates (high specificity) and 'abnormal' values with high rates (high sensitivity) might be useful from a public health perspective, especially with regard to intensity of follow-up and treatment of modifiable risk factors.

\section{KARGER}

Fax +41613061234 E-Mail karger@karger.ch www.karger.com
(C) 2011 S. Karger AG, Basel

0250-8095/11/0346-0505\$38.00/0

Accessible online at:

www.karger.com/ajn
Robert N. Foley, MB

Chronic Disease Research Group, Minneapolis Medical Research Foundation

914 South 8th Street, Suite S-406

Minneapolis, MN 55404 (USA)

Tel. +1 612347 5979, E-Mail rfoley@cdrg.org 
Regarding kidney function and cardiovascular events in the general population, much is unknown. For example, recognizing that gains in sensitivity are necessarily accompanied by losses in specificity, what threshold levels of serum creatinine and serum creatinine-based estimated glomerular filtration rate (eGFR) optimally separate people destined to develop cardiovascular events from those who are not? Which optimum kidney function threshold provides the greatest degree of discrimination? Are optimum threshold values the same in major demographic segments of the community? As declining kidney function tends to co-segregate with other classic cardiovascular risk factors, is it more efficient to screen for factors like lipid levels, body mass index, blood pressure, and blood glucose? In this long-term, communitybased study, a receiver operating characteristic approach [4] was used to identify thresholds with maximum sensitivity and specificity values, and classification tree methodology was used to assess the performance of serum creatinine, eGFR, and classic cardiovascular risk factors as discriminators of cardiovascular events and death.

\section{Methods}

\section{Objectives}

Regarding serum creatinine levels and eGFR calculated by the Chronic Kidney Disease Epidemiology Collaboration (CKD-EPI) [5], Modification of Diet in Renal Disease (MDRD) Study [6], and Cockcroft-Gault corrected for body surface area (CG/BSA) [7] equations in community-dwelling adults aged 45 to 64 years, the objectives of this study were as follows:

(1) To identify and compare threshold values of maximum combined sensitivity and specificity $\left(\mathrm{Max}_{\mathrm{Sn}+\mathrm{Sp}}\right)$ for predicting the composite outcome of coronary heart disease, stroke, or death;

(2) To perform analyses similar to those described in objective 1 for each of the separate components of the composite event;

(3) Based on $\mathrm{Max}_{\mathrm{Sn}+\mathrm{Sp}}$ for the composite event, to use classification tree analysis to consider renal function thresholds in a framework that also considered classic cardiovascular risk factors, especially those recommended for screening in communitydwelling adults.

\section{Subjects and Measurements}

Detailed study information can be found at the Atherosclerosis Risk in Communities (ARIC) Study website [8]. ARIC is a prospective, longitudinal, community-based study of cardiovascular disease in four US communities [9]. Probability-based sampling methods were used in three of these communities (Forsyth County, N.C.; Washington County, Md.; Minneapolis, Minn.); in the fourth (Jackson, Miss.), driver's license and state identification card lists were used to select a representative group of AfricanAmerican residents. Baseline examinations were performed between 1987 and 1989 and repeated at 3-year intervals.
The population for this study consisted of participants with measured serum creatinine levels, 15,582 of the original 15,732 participants (99.0\%). Serum creatinine levels, measured with the modified kinetic Jaffe-picric acid method from frozen serum samples at the ARIC central laboratory (University of Minnesota), were corrected for interlaboratory difference by subtraction of $0.24 \mathrm{mg} / \mathrm{dl}$ and standardized to the isotope dilution-mass spectrometry-traceable Roche enzymatic method by multiplication by $0.95[10-12]$. Body surface area was calculated from the formula of du Bois and du Bois [13]. Estimated GFR CKD-EPI $_{2}(\mathrm{ml} / \mathrm{min} /$ $1.73 \mathrm{~m}^{2}$ ) was calculated from standardized serum creatinine ( $\mathrm{Scr}$, $\mathrm{mg} / \mathrm{dl})$ as follows [5]:

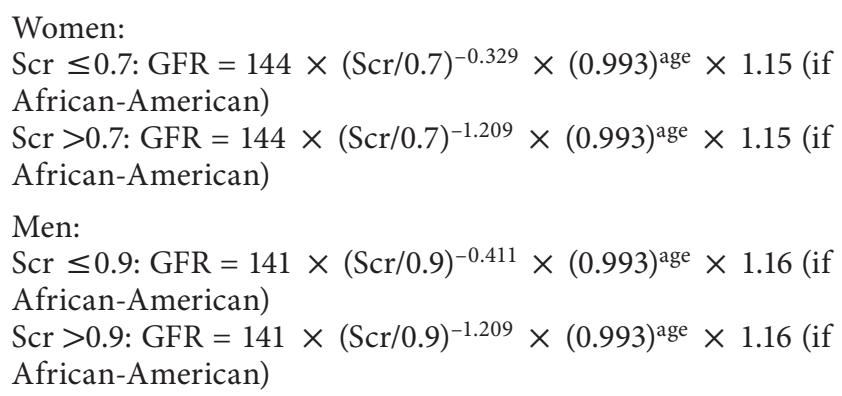

$\mathrm{eGFR}_{\text {MDRD }}\left(\mathrm{ml} / \mathrm{min} / 1.73 \mathrm{~m}^{2}\right)$ was calculated as $175 \times$ $(\mathrm{Scr})^{-1.154} \times$ age $^{-0.203} \times(0.742$ if female) $\times 1.212$ (if AfricanAmerican) [6]; eGFR $\mathrm{CG/BSA}$ was calculated from serum creatinine, age (years), sex, weight $(\mathrm{kg})$, and body-surface area $\left(\mathrm{m}^{2}\right)$ as $(1.73 /$ $\mathrm{BSA}) \times[(140-$ age $) \times$ weight $] /(72 \times \mathrm{Scr}) \times 0.85$ (if female) $[7]$. Hypertension was defined as systolic blood pressure $\geq 140 \mathrm{~mm}$ $\mathrm{Hg}$, diastolic blood pressure $\geq 90 \mathrm{~mm} \mathrm{Hg}$, or current antihypertensive medication. Diabetes was defined by self-report, medication use, fasting blood glucose $\geq 126 \mathrm{mg} / \mathrm{dl}$, or any blood glucose level $\geq 200 \mathrm{mg} / \mathrm{dl}$. Baseline coronary heart disease was defined as physician-diagnosed history of heart attack, prior myocardial infarction by electrocardiogram, prior cardiovascular surgery, or coronary angioplasty.

\section{Analysis}

Median follow-up was 13.1 years. Cardiovascular event ascertainment methodology and validation findings have been published previously [14]. Coronary heart disease events were defined as probable myocardial infarction, definite myocardial infarction, silent myocardial infarction discovered by electrocardiography between examinations, death from definite coronary heart disease, or coronary revascularization. Hemorrhagic or thrombotic strokes were defined as probable or definite events. For this study, the main study outcome was a composite event defined by the earliest occurrence of coronary heart disease, stroke, or death.

Regarding the clinical outcomes, to identify $\mathrm{Max}_{\mathrm{Sn}+\mathrm{Sp}}$ levels for Scr and eGFR at different thresholds (X), sensitivity (creatinine $>X$, eGFR $\leq \mathrm{X}$ among subjects with the event) and specificity (creatinine $\leq \mathrm{X}$, eGFR $>\mathrm{X}$ among subjects without the event) were computed separately for thresholds that varied in $0.01 \mathrm{mg} / \mathrm{l}$ increments, between 0.5 and 2.0 , for serum creatinine and in $1 \mathrm{ml} / \mathrm{min} / 1.73 \mathrm{~m}^{2}$ increments, between 50 and 120, for eGFR; only $\mathrm{Max}_{\mathrm{Sn}+\mathrm{Sp}}$ levels with $\mathrm{p}<0.05$ with logistic regression were considered valid.

Several subgroup analyses and sensitivity analyses were performed. As the discriminatory power of renal parameters might reflect associations with demographic or classic cardiovascular 
Table 1. Baseline characteristics of the study population at study inception $(\mathrm{n}=15,582)$

\begin{tabular}{|c|c|}
\hline Serum creatinine, $\mathrm{mg} / \mathrm{dl}$ & $0.83 \pm 0.40(0.15-16.97)$ \\
\hline $\mathrm{eGFR}_{\text {CKD-EPI }}, \mathrm{ml} / \mathrm{min} / 1.73 \mathrm{~m}^{2}$ & $95.7 \pm 15.5(2.5-181.3)$ \\
\hline $\mathrm{eGFR}_{\mathrm{MDRD}}, \mathrm{ml} / \mathrm{min} / 1.73 \mathrm{~m}^{2}$ & $98.6 \pm 22.7(2.9-641.8)$ \\
\hline $\mathrm{eGFR}_{\mathrm{CG} / \mathrm{BSA}}, \mathrm{ml} / \mathrm{min} / 1.73 \mathrm{~m}^{2}$ & $99.7 \pm 22.9(4.8-418.6)$ \\
\hline Age, years & $54.2 \pm 5.7(45.0-64.0)$ \\
\hline Female sex, $\%$ & 55.1 \\
\hline \multicolumn{2}{|l|}{ Race, \% } \\
\hline White & 73.6 \\
\hline African-American & 26.4 \\
\hline$<12$ years of school, $\%$ & 23.8 \\
\hline Pack-years of smoking & $16.1 \pm 21.8(0.0-242.6)$ \\
\hline Current cigarette smoker, $\%$ & 26.2 \\
\hline Ethanol intake, g/week & $42.5 \pm 96.2(0.0-1,856.0)$ \\
\hline Hypertension, \% & 34.8 \\
\hline Antihypertensive medication, $\%$ & 30.5 \\
\hline Diabetes, $\%$ & 11.8 \\
\hline Coronary heart disease, $\%$ & 5.0 \\
\hline Body mass index & $27.7 \pm 5.4(14.2-65.9)$ \\
\hline Body surface area, $\mathrm{m}^{2}$ & $1.88 \pm 0.21(1.33-2.62)$ \\
\hline LDL cholesterol, mg/dl & $137.7 \pm 39.4(0.0-504.6)$ \\
\hline HDL cholesterol, mg/dl & $51.6 \pm 17.1(9.6-163.0)$ \\
\hline Triglycerides, mg/dl & $131.9 \pm 90.5(24.0-1,928.0)$ \\
\hline Glucose, mg/dl & $109.0 \pm 40.6(35.0-628.0)$ \\
\hline Systolic blood pressure, $\mathrm{mm} \mathrm{Hg}$ & $121.3 \pm 18.9(61.0-246.0)$ \\
\hline Diastolic blood pressure, $\mathrm{mm} \mathrm{Hg}$ & $73.7 \pm 11.3(0.0-144.00)$ \\
\hline
\end{tabular}

Data are expressed as mean \pm standard deviation (range) or column percentages.

Missing data (n): eGFR $\mathrm{CG}_{\mathrm{BSA}}, 13$; years of school, 26; packyears of smoking, 276; current cigarette smoking status, 15; ethanol intake, 89; hypertension, 74; antihypertensive medication use, 8; diabetes, 29; coronary heart disease, 322; body mass index, 13; body surface area, 13; LDL cholesterol, 335; HDL cholesterol, 109; triglycerides, 108; systolic blood pressure, 7; diastolic blood pressure, 7 .

risk factors, we constructed a classification tree for the composite outcome based on the highest $\mathrm{Max}_{\mathrm{Sn}+\mathrm{Sp}}$ value when all variables were considered simultaneously, with the additional proviso of $\mathrm{p}<0.05$, for association with the composite outcome, using logistic regression. Renal variables were handled as detailed in the preceding paragraph; for other continuous variables, thresholds were changed in one-unit increments in the following ranges: age, 4663 years; pack-years of smoking, 1-60; alcohol intake, 25-250 g/ week; body mass index (calculated as $\mathrm{kg} / \mathrm{m}^{2}$ ), 20-40; low-density lipoprotein (LDL) cholesterol, 70-200 mg/dl; high-density lipoprotein (HDL) cholesterol, 30-80 mg/dl; triglycerides, 50-250 $\mathrm{mg} / \mathrm{dl}$; glucose, $85-170 \mathrm{mg} / \mathrm{dl}$; systolic blood pressure, $90-150 \mathrm{~mm}$ $\mathrm{Hg}$; diastolic blood pressure, $60-100 \mathrm{~mm} \mathrm{Hg}$. The first two iterations of this process were used to define six subgroups based on $\operatorname{Max}_{\mathrm{Sn}+\mathrm{Sp}}$ values for association with the composite outcome. In addition, subgroups were defined by sex, race, and presence of characteristics typically associated with renal dysfunction, name-

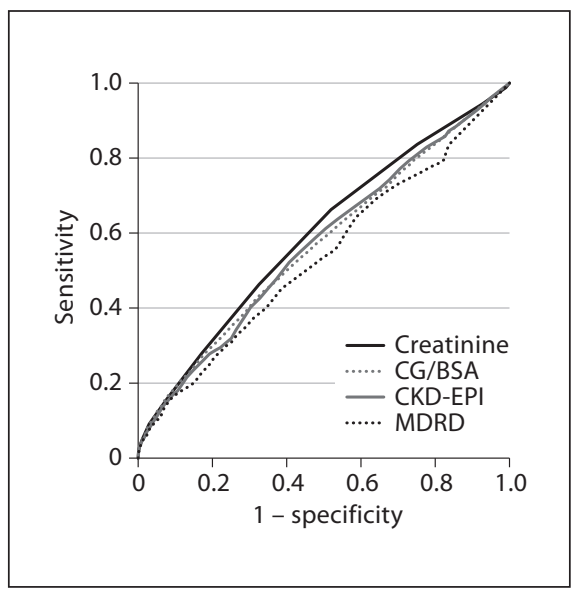

Fig. 1. Receiver-operator characteristic curves for associations between serum creatinine, eGFR, and the composite outcome. C-statistic values were 0.60 for serum creatinine, 0.57 for eGFR $_{\text {CKD-EPI }}, 0.57$ for eGFR ${ }_{C G / B S A}$, and 0.54 for eGFR ${ }_{M D R D}$.

ly diabetes, hypertension, or coronary heart disease. This study examined event occurrence at any time during the follow-up period, without considering time to event. Findings were similar when follow-up was truncated at 5 and 10 years, and are not reported here. Additionally, the classification tree approach was extended to five orders of dichotomization, generating 32 terminal subgroups. Terminal subgroups were then used to classify the entire population and both logistic regression and Cox regression were used to calculate risk ratios for the composite event; risk ratios with all strategies were very were similar and only findings based on the first iteration of the classification tree and logistic regression are reported here. SAS, version 9.1 (SAS Institute Inc., Cary, N.C., USA) was used for data analysis.

\section{Results}

The mean age of the study population (ARIC, $\mathrm{n}=$ 15,582) was 54.2 years; $55.1 \%$ were women and $26.4 \%$ were African-American (table 1). Mean standardized creatinine value was $0.83 \mathrm{mg} / \mathrm{dl}$. Mean eGFR values were $95.7 \mathrm{ml} / \mathrm{min} / 1.73 \mathrm{~m}^{2}$ using the CKD-EPI estimating equation (eGFR $\mathrm{CKD}_{\text {-EPI }}$ ) [5], $98.6 \mathrm{ml} / \mathrm{min} / 1.73 \mathrm{~m}^{2}$ using the MDRD Study estimating equation (eGFR $\mathrm{MDRD}_{\text {) }}$ [6], and $99.7 \mathrm{ml} / \mathrm{min} / 1.73 \mathrm{~m}^{2}$ using the Cockcroft-Gault corrected for body-surface area estimating equation (eGFR ${ }_{\mathrm{CG} / \mathrm{BSA}}$ ) [7].

The median follow-up was 13.1 years. During this period, $12.7 \%$ of the study population experienced a coronary heart disease event, $4.1 \%$ experienced a stroke, $13.3 \%$ died, and $22.1 \%$ experienced a composite of at least one 


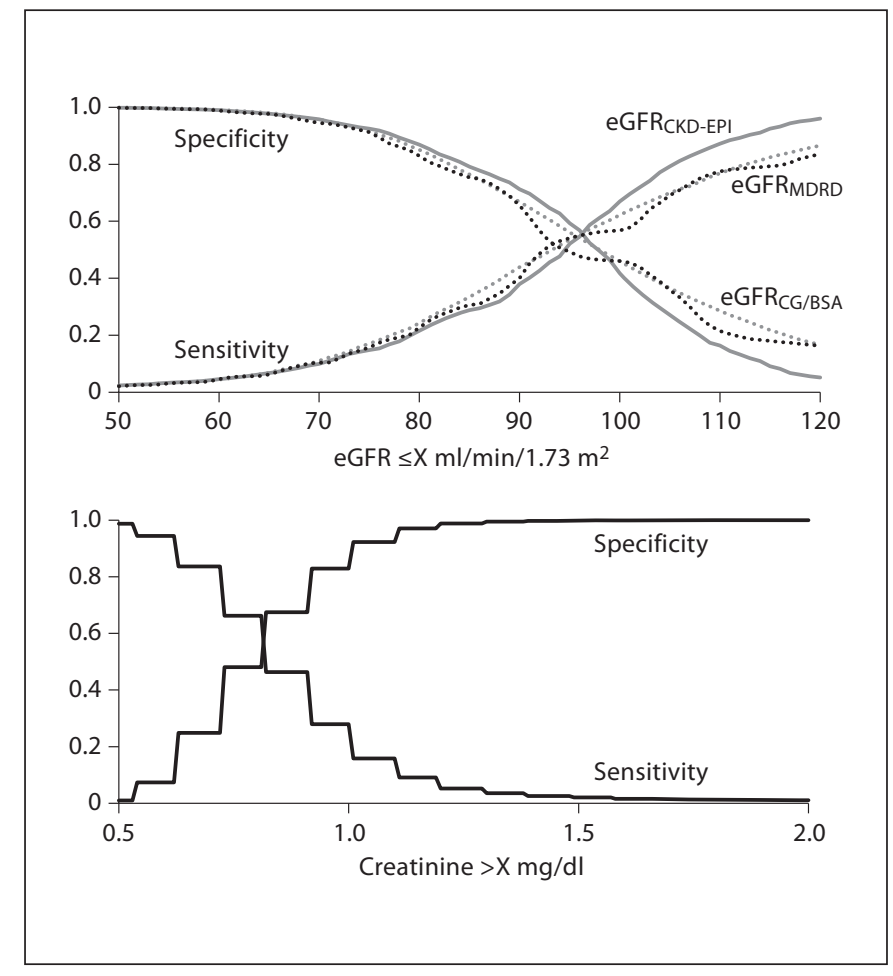

Fig. 2. Sensitivity and specificity values of different eGFR and serum creatinine values for association with the composite outcome.

of these events (the primary study outcome). Receiver operator characteristic curves for associations between serum creatinine, eGFR, and the composite outcome are shown in figure $1 ; \mathrm{c}$-statistic values were highest for serum creatinine $(0.60)$, followed by eGFR $\mathrm{CKK}_{\text {-EPI }}(0.57)$, $\mathrm{eGFR}_{\mathrm{CG} / \mathrm{BSA}}$ (0.57), and eGFR $\mathrm{MDRD}_{\mathrm{D}}(0.54)$.

Corresponding c-statistics for the individual components of the composite outcome are shown in table 2 . For coronary heart disease, values were 0.62 for serum creatinine, 0.58 for eGFR $\mathrm{CKD}_{\text {-EPI}}, 0.56$ for eGFR $\mathrm{CG}_{\mathrm{BSA}}$, and 0.56 for eGFR $\mathrm{MDRD}_{\text {. For cerebrovascular accident, values }}$ were 0.57 for serum creatinine, 0.55 for eGFR $\mathrm{CG}_{\mathrm{BSA}}, 0.54$

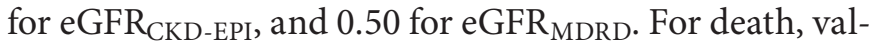
ues were 0.59 for $\mathrm{eGFR}_{\mathrm{CG} / \mathrm{BSA}}, 0.58$ for serum creatinine, 0.57 for eGFR $\mathrm{CKD}_{\mathrm{CPP}}$, and 0.53 for eGFR $\mathrm{MDRD}_{\text {. }}$

Regarding associations with the composite outcome, figure 2 shows sensitivity and specificity values of different renal function thresholds for the composite outcome, and table 2 ranks $\mathrm{Max}_{\mathrm{Sn}+\mathrm{Sp}}$ values. For all eGFR measures, sensitivity was below 0.05 and specificity above 0.98 for thresholds of $60 \mathrm{ml} / \mathrm{min} / 1.73 \mathrm{~m}^{2}$. For serum creatinine, $\operatorname{Max}_{\mathrm{Sn}+\mathrm{Sp}}$ occurred at a level of $0.73 \mathrm{mg} / \mathrm{dl}$ (sen- sitivity $0.66 /$ specificity 0.48 ); corresponding values for eGFR $_{\text {CKD-EPI, }}$ eGFR $\mathrm{CG}_{\mathrm{BSA}}$, and eGFR ${ }_{\mathrm{MDRD}}$ were $95 \mathrm{ml} /$ $\mathrm{min} / 1.73 \mathrm{~m}^{2}(0.52 / 0.59), 90 \mathrm{ml} / \mathrm{min} / 1.73 \mathrm{~m}^{2}$ (0.44/0.67), and $75 \mathrm{ml} / \mathrm{min} / 1.73 \mathrm{~m}^{2}(0.16 / 0.91)$, respectively. Findings were generally comparable when the components of the composite event were considered separately, with broadly similar $\operatorname{Max}_{S n+S p}$ values for optimum serum creatinine, $e G_{C K R} R_{C-E P I}$, and eGFR ${ }_{C G / B S A}$ thresholds, lower values for optimum eGFR $\mathrm{MDRD}_{\mathrm{T}}$ thresholds, and relatively higher specificity than sensitivity for $\mathrm{GFFR}_{\mathrm{MDRD}}$.

We also calculated c-statistic values for association with the composite outcome in subgroups defined by demographic characteristics, and in subgroups defined by dominant prognostic association (data not shown). Findings generally paralleled findings in the overall populations, with approximately similar performance of serum creatinine, eGFR $\mathrm{CKD}_{\mathrm{EPI}}$, and eGFR $\mathrm{CG}_{\mathrm{BSA}}$, and inferior performance of $\mathrm{eGFR}_{\mathrm{MDRD}}$. Regarding thresholds of $\mathrm{Max}_{\mathrm{Sn}+\mathrm{Sp}}$, values were typically higher than 60 $\mathrm{ml} / \mathrm{min} / 1.73 \mathrm{~m}^{2}$ for eGFR and below 1.0 for serum creatinine.

Table 3 shows findings from the first iteration of the classification tree analysis for the composite outcome, with threshold values ranked by $\mathrm{Max}_{\mathrm{Sn}+\mathrm{Sp}}$. Eighteen or more pack-years of smoking was the highest ranked of 20 risk factors identified in the overall population; creatinine $>0.73 \mathrm{mg} / \mathrm{dl}$ ranked tenth, eGFR CKD-EPI $\leq 95 \mathrm{ml} /$ $\mathrm{min} / 1.73 \mathrm{~m}^{2}$ fifteenth, eGFR $\mathrm{CG}_{\mathrm{BSA}} \leq 90 \mathrm{ml} / \mathrm{min} / 1.73 \mathrm{~m}^{2}$ sixteenth, and $e G_{\text {MDRD }} \leq 75 \mathrm{ml} / \mathrm{min} / 1.73 \mathrm{~m}^{2}$ eighteenth. When 10 modifiable risk factors were considered, HDL cholesterol $\leq 44 \mathrm{mg} / \mathrm{dl}$ ranked first, creatinine $>0.73 \mathrm{mg} / \mathrm{dl}$ tenth, eGFR $\mathrm{CKD \text {-EPI }} \leq 95 \mathrm{ml} / \mathrm{min} / 1.73 \mathrm{~m}^{2}$ sixth, eGFR $\mathrm{CG}_{\text {BSA }} \leq 90 \mathrm{ml} / \mathrm{min} / 1.73 \mathrm{~m}^{2}$ seventh, and $\mathrm{eGFR}_{\mathrm{MDRD}} \leq 75 \mathrm{ml} / \mathrm{min} / 1.73 \mathrm{~m}^{2}$ ninth.

\section{Discussion}

In this community-based study of older adults, we found that creatinine-based thresholds exhibiting maximum combined sensitivity and specificity values for predicting cardiovascular events and death rates were substantially higher than $60 \mathrm{ml} / \mathrm{min} / 1.73 \mathrm{~m}^{2}$, with the latter threshold distinguished by very low sensitivity and high specificity. In addition, we found that optimum thresholds based on serum creatinine appeared to perform similarly to eGFR thresholds. Regarding eGFR thresholds, those based on the MDRD Study formula appeared less efficient than those based on the other formulas. Finally, threshold renal function measures did not appear to be 
Table 2. Renal function markers as continuous variables, ranked by c-statistic values, and threshold values of maximum combined sensitivity and specificity for composite event, coronary heart disease, cerebrovascular accident, and death, ranked by maximum combined sensitivity and specificity

\begin{tabular}{|c|c|c|c|c|}
\hline Rank & $\begin{array}{l}\text { Composite event }{ }^{\mathrm{a}} \\
(3,441 / 15,582 \text { events })\end{array}$ & $\begin{array}{l}\text { Coronary heart disease } \\
(1,975 / 15,582 \text { events })\end{array}$ & $\begin{array}{l}\text { Cerebrovascular accident } \\
(633 / 15,582 \text { events })\end{array}$ & $\begin{array}{l}\text { Death } \\
(2,077 / 15,582 \text { events })\end{array}$ \\
\hline \multicolumn{5}{|c|}{ Continuous variables ranked by c-statistics } \\
\hline 1 & creatinine 0.60 & creatinine 0.62 & creatinine 0.57 & $\mathrm{eGFR}_{\mathrm{CG} / \mathrm{BSA}} 0.59$ \\
\hline 2 & $\mathrm{eGFR}_{\mathrm{CKD} \text {-EPI }} 0.57$ & $\mathrm{eGFR}_{\mathrm{CKD} \text {-EPI }} 0.58$ & $\mathrm{eGFR}_{\mathrm{CG} / \mathrm{BSA}} 0.55$ & creatinine 0.58 \\
\hline 3 & $\mathrm{eGFR}_{\mathrm{CG} / \mathrm{BSA}} 0.57$ & $\mathrm{eGFR}_{\mathrm{CG} / \mathrm{BSA}} 0.56$ & $\mathrm{eGFR}_{\mathrm{CKD} \text {-EPI }} 0.54$ & $\mathrm{eGFR}_{\mathrm{CKD} \text {-EPI }} 0.57$ \\
\hline 4 & $\mathrm{eGFR}_{\mathrm{MDRD}} 0.54$ & $\mathrm{eGFR}_{\mathrm{MDRD}} 0.56$ & $\mathrm{eGFR}_{\mathrm{MDRD}} 0.50$ & $\mathrm{eGFR}_{\text {MDRD }} 0.53$ \\
\hline \multicolumn{5}{|c|}{ Threshold values ranked by $\operatorname{Max}_{S n+S p}$} \\
\hline 1 & creatinine $>0.73(0.66 / 0.48)$ & creatinine $>0.73(0.71 / 0.47)$ & $\mathrm{eGFR}_{\mathrm{CG} / \mathrm{BSA}} \leq 86(0.38 / 0.73)$ & $\mathrm{eGFR}_{\mathrm{CG} / \mathrm{BSA}} \leq 89(0.46 / 0.68)$ \\
\hline 2 & $\mathrm{eGFR}_{\text {CKD-EPI }} \leq 95(0.52 / 0.59)$ & $\mathrm{eGFR}_{\mathrm{CKD}-\mathrm{EPI}} \leq 97(0.61 / 0.52)$ & creatinine $>0.82(0.46 / 0.65)$ & $\mathrm{eGFR}_{\text {CKD-EPI }} \leq 95(0.53 / 0.58)$ \\
\hline 3 & $\mathrm{eGFR}_{\mathrm{CG} / \mathrm{BSA}} \leq 90(0.44 / 0.67)$ & $\mathrm{eGFR}_{\mathrm{CG} / \mathrm{BSA}} \leq 90(0.43 / 0.66)$ & $\mathrm{eGFR}_{\mathrm{CKD}-\mathrm{EPI}} \leq 92(0.44 / 0.65)$ & creatinine $>0.82(0.45 / 0.66)$ \\
\hline 4 & $\mathrm{eGFR}_{\mathrm{MDRD}} \leq 75(0.16 / 0.91)$ & $-{ }^{b}$ & $\mathrm{eGFR}_{\mathrm{MDRD}} \leq 74(0.16 / 0.91)$ & $\mathrm{eGFR}_{\mathrm{MDRD}} \leq 75(0.18 / 0.91)$ \\
\hline
\end{tabular}

Numbers in parentheses are sensitivity/specificity.

a Any event: coronary heart disease, cerebrovascular accident, or death.

${ }^{b}$ For eGFR $\mathrm{MDRD}_{\text {D }}$ threshold with $\mathrm{Max}_{\mathrm{Sn}+\mathrm{Sp}}, \mathrm{p}>0.05$ for association with coronary heart disease.

Table 3. First iteration of classification tree analysis, composite outcome, threshold values ranked by $\mathrm{Max}_{\mathrm{Sn}+\mathrm{Sp}}{ }^{\mathrm{a}}$

\begin{tabular}{|c|c|c|c|c|c|}
\hline Rank & Risk factor ${ }^{b}$ & Prevalence, $\%^{c}$ & $\begin{array}{l}\text { Sensitivity/ } \\
\text { specificity }\end{array}$ & $\begin{array}{l}\text { Odds ratio } \\
(95 \% \mathrm{CI})^{\mathrm{d}}\end{array}$ & $\mathrm{p}^{\mathrm{d}}$ \\
\hline 1 & $>18$ pack-years & 35.1 & $0.54 / 0.70$ & $1.7(1.4-2.0)$ & $<0.001$ \\
\hline 2 & Male sex & 44.9 & $0.62 / 0.60$ & $1.5(1.2-1.7)$ & $<0.001$ \\
\hline 3 & Age $>53$ years & 52.3 & $0.69 / 0.53$ & $2.2(1.9-2.6)$ & $<0.001$ \\
\hline 4 & HDL cholesterol $\leq 44 \mathrm{mg} / \mathrm{dl}$ & 37.6 & $0.53 / 0.67$ & $1.4(1.2-1.6)$ & $<0.001$ \\
\hline 5 & Treatment for hypertension & 30.5 & $0.44 / 0.73$ & $2.6(2.2-3.1)$ & $<0.001$ \\
\hline 6 & Hypertension & 34.8 & $0.48 / 0.69$ & $3.5(3.0-4.2)$ & $<0.001$ \\
\hline 7 & Glucose $>106 \mathrm{mg} / \mathrm{dl}$ & 27.8 & $0.40 / 0.76$ & $2.1(1.8-2.5)$ & $<0.001$ \\
\hline 8 & Triglycerides $>110 \mathrm{mg} / \mathrm{dl}$ & 49.6 & $0.62 / 0.54$ & $1.5(1.2-1.7)$ & $<0.001$ \\
\hline 9 & Diabetes & 11.8 & $0.23 / 0.92$ & $3.4(2.9-4.1)$ & $<0.001$ \\
\hline 10 & Creatinine $>0.73 \mathrm{mg} / \mathrm{dl}$ & 55.1 & $0.66 / 0.48$ & $1.5(1.3-1.8)$ & $<0.001$ \\
\hline 11 & Current smoker & 26.2 & $0.37 / 0.77$ & $1.7(1.4-2.0)$ & $<0.001$ \\
\hline 12 & $<12$ years of school & 23.8 & $0.34 / 0.79$ & $2.3(2.0-2.7)$ & $<0.001$ \\
\hline 13 & Coronary heart disease & 5.0 & $0.15 / 0.98$ & $2.8(2.2-3.6)$ & $<0.001$ \\
\hline 14 & LDL cholesterol >136 mg/dl & 49.2 & $0.58 / 0.53$ & $1.3(1.1-1.5)$ & 0.003 \\
\hline 15 & $\mathrm{eGFR}_{\mathrm{CKD}-\mathrm{EPI}} \leq 95 \mathrm{ml} / \mathrm{min} / 1.73 \mathrm{~m}^{2}$ & 43.2 & $0.52 / 0.59$ & $1.4(1.2-1.6)$ & $<0.001$ \\
\hline 16 & $\mathrm{eGFR}_{\mathrm{CG} / \mathrm{BSA}} \leq 90 \mathrm{ml} / \mathrm{min} / 1.73 \mathrm{~m}^{2}$ & 35.5 & $0.44 / 0.67$ & $1.5(1.3-1.8)$ & $<0.001$ \\
\hline 17 & Body mass index $>27$ & 49.1 & $0.55 / 0.53$ & $1.7(1.4-2.0)$ & $<0.001$ \\
\hline 18 & $\mathrm{eGFR}_{\mathrm{MDRD}} \leq 75 \mathrm{ml} / \mathrm{min} / 1.73 \mathrm{~m}^{2}$ & 10.3 & $0.16 / 0.91$ & $1.7(1.3-2.1)$ & $<0.001$ \\
\hline 19 & Ethanol intake $>120 \mathrm{~g} /$ week & 11.7 & $0.14 / 0.89$ & $1.3(1.0-1.6)$ & 0.04 \\
\hline 20 & African-American & 26.4 & $0.28 / 0.74$ & $2.2(1.9-2.6)$ & $<0.001$ \\
\hline
\end{tabular}

a Any event: coronary heart disease, cerebrovascular accident, or death.

${ }^{b}$ For each risk factor, the reference group is participants without the condition of interest.

${ }^{c}$ The proportion of the population or subgroup with the condition of interest.

${ }^{\mathrm{d}}$ From logistic regression, with the composite variable as outcome. 
the dominant prognostic discriminators in the overall population or in the subgroups assessed. If confirmed, these findings suggest that creatinine-based estimates may not be very useful for prognostic triage and, by extension, that routine measurement in community-dwelling adults may not be an efficient strategy for predicting these diseases.

The analytical approach used in this study was based on an effort to identify measures and thresholds of kidney function that outperformed competing renal and non-renal candidate variables. Selection of a dominant entity was based on the mathematical construct of maximum combined sensitivity and specificity values. Hence, risk factor prevalence weighed heavily into the selection process. Because this approach is hierarchical, it allows comparisons of different threshold values of a single risk factor; in addition, it facilitates comparisons of optimum threshold values of multiple risk factors. Both these attributes might be useful for risk-based triage in public health settings. This study suggests that even valid tests of kidney function have modest sensitivity for predicting cardiovascular events and death. This is not surprising, given the complex etiologies of these conditions.

Associations between kidney function, cardiovascular disease, and death have been studied extensively. For example, a PubMed search of human studies carried out in September 2010 with the search terms mortality or survival or cardiovascular, and glomerular filtration rate or creatinine or chronic kidney disease, and community or general population yielded 2,156 citations, a value that fell to 140 with the addition of 'sensitivity and specificity' and to four with the addition of 'threshold', with none of these four articles directly relevant to the questions addressed in the current study. Hence, it appears that few studies have attempted to define threshold levels of kidney function that maximally discriminate between occurrence, or not, of major cardiovascular events over finite intervals. One exception was an examination of 50-year-old Swedish men, in which optimum creatinine clearance thresholds for myocardial infarction and cardiovascular death were 98 and $92 \mathrm{ml} /$ $\min / 1.73 \mathrm{~m}^{2}$, respectively [15]. Our group recently reported mortality-kidney function profiles from US adults studied between 1988 and 1994 in the third National Health and Nutrition Examination Survey

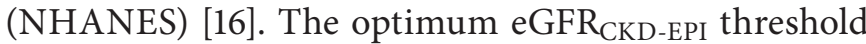
for death/survival discrimination, $94 \mathrm{ml} / \mathrm{min} / 1.73 \mathrm{~m}^{2}$, was similar to the threshold seen in the current study, and the optimum urinary albumin-creatinine ratio,
$9 \mathrm{mg} / \mathrm{g}$, was substantially lower than the thresholds used to define abnormality in most classification systems. Unlike in this study, the albumin-creatinine ratio and eGFR appeared to compare favorably with other classic risk factors for risk triage. A limitation of the previous study was nonavailability of most components of major adverse cardiovascular end points, such as coronary heart disease and stroke; in addition, optimally discriminatory serum creatinine thresholds were not studied. The reasons underlying the disparity in discriminatory efficiency of renal function measures between the two studies are not clear. This being said, it is tempting to speculate that the age bands studied (all adults in NHANES, ages 45-65 years in ARIC) may be partly responsible. In this regard, it is also tempting to speculate that the nonsuperior mortality discrimination of eGFR over serum creatinine also reflects the comparatively narrow age distribution of the study population.

The limitations of the current study deserve consideration. Findings were generated from four populations in the US between 1987 and 1989 and generalizability to other populations is uncertain. Gold-standard techniques, such as inulin and radioisotope clearance, were not available for GFR measurement. Urinary protein excretion information was not available. As with virtually all studies reported to date, kidney function in this study was measured on one occasion. In clinical practice, an eGFR or serum creatinine test suggesting the presence of chronic kidney disease would require a confirmatory test, as current guidelines for case finding suggest that abnormalities should be present for at least 3 months for case definition [17]. This study was based on a single assessment of GFR. As GFR values vary substantially from one time point to another, it is conceivable that sensitivity values may be higher if a strategy of multiple GFR assessments had been used.

Despite its limitations, this study has some attractive features. The study was community based and designed to be broadly representative. Several commonly used risk triage measures, such as cholesterol, blood pressure, and body mass index were systematically collected at the same time that renal function was measured, and a single creatinine measurement technique was used. While confirmation is needed, this study suggests that optimum thresholds for risk identification are higher than the value currently used to define a moderately abnormal GFR $\left(60 \mathrm{ml} / \mathrm{min} / 1.73 \mathrm{~m}^{2}\right)$. The utility of creatinine-based risk triage in older adults in community settings appears modest. 


\section{Acknowledgments}

This study was supported by the Minneapolis Medical Research Foundation. The authors thank Chronic Disease Research Group colleagues Shane Nygaard, BA, for manuscript preparation, and Nan Booth, MSW, MPH, ELS, for manuscript editing.

\section{Disclosure Statement}

The authors have no conflicts of interest.

\section{References}

1 National Kidney Foundation: K/DOQI clinical practice guidelines for chronic kidney disease: evaluation, classification, and stratification. Am J Kidney Dis 2002;39:S1-S266.

-2 Levey AS, Eckardt KU, Tsukamoto Y, et al: Definition and classification of chronic kidney disease: a position statement from Kidney Disease: Improving Global Outcomes (KDIGO). Kidney Int 2005;67:2089-2100.

-3 Sarnak MJ, Levey AS, Schoolwerth AC, et al: Kidney disease as a risk factor for development of cardiovascular disease: a statement from the American Heart Association Councils on Kidney in Cardiovascular Disease, High Blood Pressure Research, Clinical Cardiology, and Epidemiology and Prevention. Circulation 2003;108:2154-2169.

-4 Swets JA: The relative operating characteristic in psychology: a technique for isolating effects of response bias finds wide use in the study of perception and cognition. Science 1973;182:990-1000.

5 Levey AS, Stevens LA, Schmid CH, et al: A new equation to estimate glomerular filtration rate. Ann Intern Med 2009;150:604612.
6 Levey AS, Coresh J, Greene T, et al: Using standardized serum creatinine values in the modification of diet in renal disease study equation for estimating glomerular filtration rate. Ann Intern Med 2006; 145:247254.

7 Cockcroft DW, Gault MH: Prediction of creatinine clearance from serum creatinine. Nephron 1976;16:31-41.

8 Collaborative Studies Coordinating Center. ARIC: Atherosclerosis Risk in Communities Study. Available at: http://www.cscc.unc. edu/aric/; accessed 27 June, 2011.

$\checkmark 9$ The Atherosclerosis Risk in Communities (ARIC) Study: design and objectives. The ARIC investigators. Am J Epidemiol 1989; 129:687-702.

10 National Heart Lung and Blood Institute. Atherosclerosis Risk in Communities (ARIC) Study: Operations Manual No. 10. Clinical Chemistry Determinations. Bethesda, 1987, pp 1-76.

11 Kottgen A, Russell SD, Loehr LR, et al: Reduced kidney function as a risk factor for incident heart failure: the Atherosclerosis Risk in Communities (ARIC) Study. J Am Soc Nephrol 2007;18:1307-1315.

12 Matsushita K, Selvin E, Bash LD, Astor BC, Coresh J: Risk implications of the new CKD Epidemiology Collaboration (CKD-EPI) equation compared with the MDRD Study equation for estimated GFR: the Atherosclerosis Risk in Communities (ARIC) Study. Am J Kidney Dis 2010;55:648-659.
13 Du Bois D, Du Bois E: A formula to estimate the approximate surface area if height and weight be known. Arch Intern Med 1916;17: 863-871.

14 White AD, Folsom AR, Chambless LE, et al: Community surveillance of coronary heart disease in the Atherosclerosis Risk in Communities (ARIC) Study: methods and initial two years' experience. J Clin Epidemiol 1996; 49:223-233.

15 Soveri I, Arnlov J, Berglund L, Lind L, Fellstrom B, Sundstrom J: Kidney function and discrimination of cardiovascular risk in middle-aged men. J Intern Med 2009;266: 406-413.

16 Foley RN, Wang C, Snyder JJ, Rule AD, Collins AJ: Kidney function and risk triage in adults: threshold values and hierarchical importance. Kidney Int 2011;79:99-111.

17 National Kidney Foundation: K/DOQI Clinical Practice Guidelines for Chronic Kidney Disease: Evaluation, Classification, and Stratification. Part 4. Definition and Classification of Stages of Chronic Kidney Disease. Available at: www.kidney.org; accessed 27 June, 2011. 